\title{
Value Chain of Technology in Higher Education Institutions: From IT Resources to Technological Performance
}

\author{
Jacques Bulchand-Gidumal, Santiago Melián-González, and Javier Osorio-Acosta \\ Departamento de Economía y Dirección de Empresas, Universidad de Las Palmas de Gran \\ Canaria, Campus Universitario de Tafira, 35017 Las Palmas, Spain \\ \{Jbulchand, smelian, josorio\} @dede.ulpgc.es
}

\begin{abstract}
Different studies confirm that the presence of IT in firms, together with human and other organizational resources, has a positive influence on the performance of organizations. However, the details of the process through which that influence is produced have not been clarified. This study is based on an extensive IT data base corresponding to a sample of universities and presents an IT-technological performance value chain and confirms the hypotheses about its functioning. The result is a value chain that begins with the IT planning, passes through different components related to technology in organizations and ends with the performance of the technology. We believe that this research is useful to higher education institutions managers by allowing them to have a clear path on how to improve the return of IT investments.
\end{abstract}

Keywords: IT performance, firm performance, IT resources, IT strategic planning, Value chain, resource-based view of the firm, universities, Spain.

\section{Introduction}

Today, almost every higher education institution uses IT. Still, we know that not all of them get the same value out of IT. This is, the organizational performance is not increased in higher education institutions as the investment in IT. Some obtain more, some obtain less.

Although a lot of different explanations can be given, starting by how we measure organizational performance in the case of higher education institutions, and passing by concepts such as complementary resources (Brynjolfsson, 2003), the effect of the learning curve deferring the performance and the sample size (Hitt and Brynjolfsson, 1996; Brynjolfsson, 1998; Schreyer, 1998; Kholi and Devaraj, 2003), we understand it would be very interesting for organizations to have a path, a value chain, that defines what to do with IT investments in order to improve organizational performance. Since not many works address this issue, this article aims to clarify this question, specifically in the context of higher education institutions.

To that end, we first explain our proposed model and the data base we used to test it. This is followed by the methodology used, the results obtained and, finally, the conclusions and limitations of the work. 


\section{Preparation of the Model and Work Hypotheses}

According to Barney (1991), a firm's resources can be classified into resources of physical, human and organizational capital. Thus, as drivers of the process, those resources must appear in the initial phase of the process of IT value creation.

In a first design of our proposal, the three types of resources constitute the starting point of the chain through which IT begins to add value. Like Bharadwaj (2000), we consider that an organization's IT capability consists of organizing those three classes of resources in a way that is effective for their performance: IT strategic planning (ITPLAN), IT area human resources (ITHR) and infrastructure IT resources (ITINFR) and we understand that ITPLAN is the guiding structure that defines what to do with the other two categories, ITHR and ITINFR.

With these categories organizations are able to create IT applications (ITAPPS), guarantee system reliability (ITRELIAB) and define a series of norms for IT use (ITPROCS).

After these three items we understand we arrive to the part of the chain dealing with performance. Its position is in the final part, which is where the cited works also place it. Thus, in the analyses, we show that many of the data that we have refer to the output of the IT processes or tasks, in other words, they constitute what we finally called technological performance.

We believe there are really two kinds of technological performance: performance referring to the technology's contribution to the management of the organization (ITPERFORG) and performance related to the use of the technology by users who are not IT personnel (ITPERFUSER). Those two dimensions match the possibilities that Sambamurthy and Zmud (1994) consider for the IT impact.

So we derive a model that is presented in Figure 1.

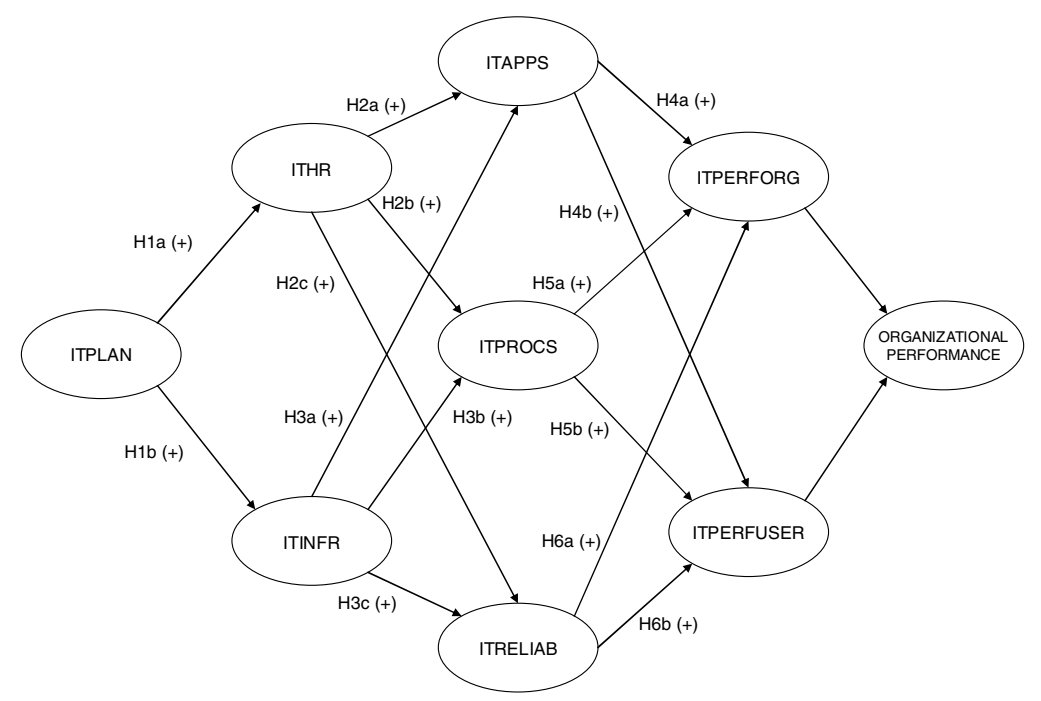

Fig. 1. Proposed model 
In this article, we are not going to test the final part of the model, but, like Sambamurthy and Zmud (1994) and Soh and Markus (1995), we propose that organizational performance will be influenced by the technological performance.

To end this section, we break down the functioning of the proposed model into hypotheses. There are many authors who indicate the need to plan the development of IT (i.e. Boar, 2001). In light of the above, our first hypothesis is the following:

H1. ITPLAN has a positive influence on the level of (a) ITHR and (b) ITINFR.

The importance of human resources to IT performance has been confirmed in various studies (Powell and Dent-Micallef, 1997; Francalanci and Galal, 1998, Bharadwaj. 2000). Therefore, we propose that the greater the deployment of IT human resources, the higher the performance in the three IT processes identified from our data base. Thus:

H2. ITHR has a positive influence on (a) ITAPPS, (b) ITPROCS and (c) ITRELIAB.

It is also logical that it is necessary to have a basic IT infrastructure in order to perform well in IT (Ross et al., 1996; Bharadwaj, 2000; Broadbent et al., 1999; Bhatt and Grover, 2005). Thus, as in the case of human resources, we consider that the physical IT resources exercise a positive influence on the three established IT processes.

H3. ITINFR has a positive influence on (a) ITAPPS, (b) ITPROCS and (c) ITRELIAB.

Moving onto the final part of the model, Cooper et al. (2000) indicate that the presence of certain management applications (e.g., datawarehouses, work flows, content and news managers) in organizations favors organizational performance. Therefore:

H4. ITAPPS has a positive influence on (a) ITPERFORG and (b) ITPERFUSER.

Secondly, Broadbent and Weill (1992) indicate that the standardization and formalization of the IT in organizations is a positive value that helps improve the organization's technological performance. Therefore, we propose that:

H5. ITPROCS has a positive influence on (a) ITPERFORG and (b) ITPERFUSER.

Finally, authors such as Teo and Ang (1999) indicate that the fact that the IT services are efficient and reliable constitutes one of the factors critical to the alignment of IT:

H6. ITRELIAB has a positive influence on (a) ITPERFORG and (b) ITPERFUSER.

\section{Description of the IT Data Base}

In order to test the model, we had access to a data base of IT data of Spanish universities that was created by the universities themselves trough their Rectors Conference (CRUE), specifically the group dedicated to IT.

The data base in question contains a vast amount of information related to IT in university institutions and has a total of 118 indicators. Table 1 shows examples of data for each of the six strategic axes in which that work group organized the information. It also includes some additional data about each institution in a specific area. 
Table 1. Structure and content of the data base

\begin{tabular}{|c|c|c|}
\hline Axes & Indicators & Examples of data \\
\hline $\begin{array}{l}\text { 1. Teaching- } \\
\text { learning }\end{array}$ & 16 & $\begin{array}{l}\text { Students per computer in classrooms, classrooms with Wi- } \\
\text { Fi coverage, institutional plan for the development of on- } \\
\text { line teaching. }\end{array}$ \\
\hline 2. Research & 19 & $\begin{array}{l}\text { Scientific calculation capability, application for research } \\
\text { management, research groups with web page. }\end{array}$ \\
\hline $\begin{array}{l}\text { 3. Management } \\
\text { processes }\end{array}$ & 12 & $\begin{array}{l}\text { Computerized management processes, backup system to } \\
\text { activate the services that suffer availability problems, e- } \\
\text { administration technologies being exploited. }\end{array}$ \\
\hline $\begin{array}{l}\text { 4. Management } \\
\text { of institutional } \\
\text { information }\end{array}$ & 21 & $\begin{array}{l}\text { Procedures available in the records management, } \\
\text { departments that use the content manager to publish on the } \\
\text { web, existence of a contingency plan in case of } \\
\text { emergencies. }\end{array}$ \\
\hline $\begin{array}{l}\text { 5. IT training } \\
\text { and culture }\end{array}$ & 21 & $\begin{array}{l}\text { Individuals on the management staff who have received } \\
\text { training in IT competencies, average budget for specialized } \\
\text { training of IT personnel, users who access the intranet } \\
\text { through a VPN. }\end{array}$ \\
\hline $\begin{array}{l}\text { 6. Organization } \\
\text { of IT }\end{array}$ & 16 & $\begin{array}{l}\text { Existence of a strategic plan for IT, IT personnel in relation } \\
\text { to number of students, incidents successfully resolved by } \\
\text { IT department in relation to number of users. }\end{array}$ \\
\hline Context data & 13 & $\begin{array}{l}\text { Administrative personnel, faculty staff, classrooms, } \\
\text { research groups, subjects, budget, staff budget. }\end{array}$ \\
\hline
\end{tabular}

Source: CRUE-TIC group

In turn, each of those six axes comprises up to a total of twenty-eight objectives. Some examples of these were:

- Axe 1, Objective 1 - To incorporate IT in the classrooms (computer and noncomputer) -9 indicators.

- Axe 2, objective 4 - To promote the expansion of research activity by means of IT tools -4 indicators.

- Axe 4, objective 2 - To be prepared to manage institutional knowledge on the basis of statistics, indicators, balanced scorecards and data analysis -2 indicators.

- Axe 5, objective 2 - To ensure specific training for IT personnel -3 indicators.

- Axe 6, objective 1 - To have strategic IT planning -3 indicators.

\section{Methodology, Data Analysis and Results}

The population of our study comprises all 73 Spanish universities, 50 of which are state universities and 23 private. Data was collected by the Rectors Conference in 2006 and 2007 through a questionnaire completed by the CIO. A total of 59 completed questionnaires were received, of which three were eliminated because they were not properly completed, giving a response rate of $76.7 \%$. The chosen method of data analysis was structural equations using the Partial Least Squares technique (PLS), specifically, we use SmartPLS 3.0 build M3 (Ringle et al., 2005). 
Our model has eight constructs, three of which have formative indicators and the other five reflective indicators. In our case, the indicators of the constructs ITHR, ITINFR, ITAPPS, ITPROCS and ITRELIAB are reflective and, therefore, should display high levels of correlation. However, the indicators of the variables ITPLAN, ITPERFORG and ITPERFUSER do not have that property, thus this constructs are considered as formative.

To test the hypotheses, it is necessary to begin by analyzing the measurement model (in other words, the relationships between the constructs and their indicators) and then the structural model (that is, the relationships between constructs). All the test were sufficiently passed by the model: individual item reliability of reflective constructs, construct reliability (Cronbach's alpha coefficient and for composite reliability), average variance extracted (AVE) and discriminant validity. Formative constructs also passed the non-multicolinearity test.

We now analyze the structural model, summarized in Figure 2. That figure shows the explained variance of the constructs $\left(R^{2}\right)$ and the standardized coefficients $(\beta)$. Other tests such as the $Q^{2}$ test for predictive relevance and the test for the stability of the estimations were all exceeded comfortably by the model.

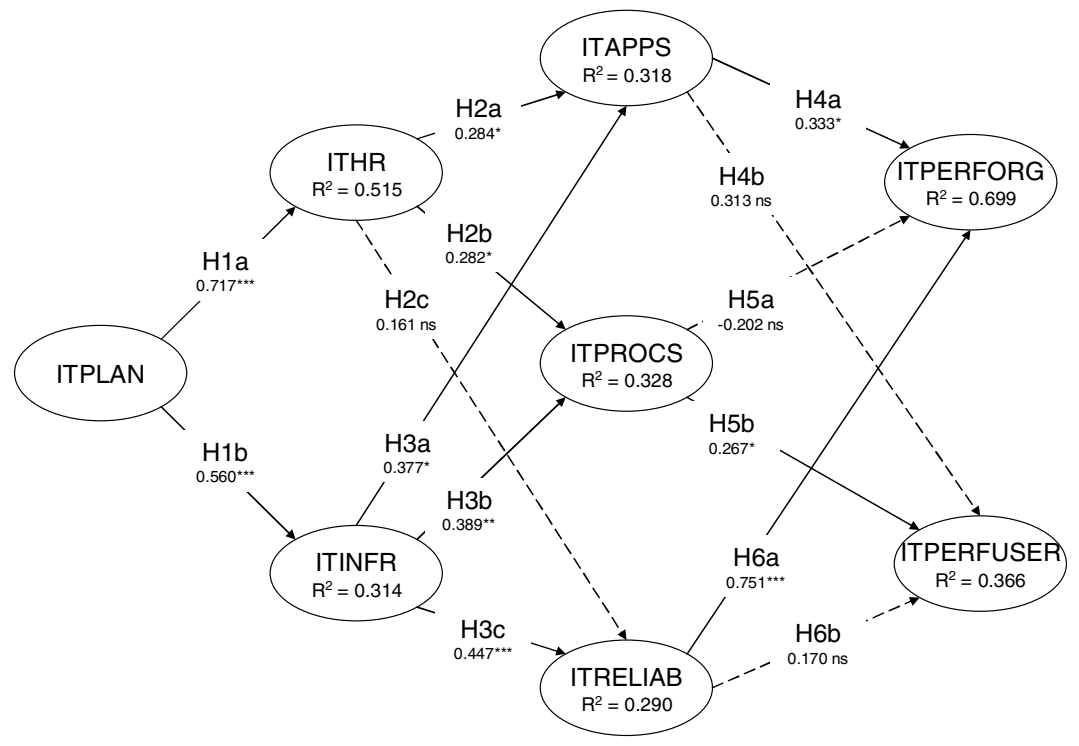

Fig. 2. Estimated causal relationships in the structural model

As can be seen, out of the 14 proposed hypotheses, 10 were confirmed and 4 were not $(\mathrm{H} 2 \mathrm{c}, \mathrm{H} 5 \mathrm{a}, \mathrm{H} 4 \mathrm{~b}$ and $\mathrm{H} 6 \mathrm{~b})$. With regard to the explained variance $\left(R^{2}\right)$ of the constructs the structural model displays adequate predictive power. The constructs obtain $R^{2}$ values that are never below 0.290 , the explained variance of the variable ITPERFORG is $69.9 \%$ and that of the variable ITPERFUSER is $36.6 \%$. 
Apart from examining the $R^{2}$, the model is evaluated by observing the predictive power $Q^{2}$ of the constructs of the model (Geisser, 1974; Stone, 1974). The model passed the test of the $Q^{2}$ being greater than 0 for the seven constructs.

As figure 2 shows, the model predicts $51.5 \%$ of the variance of the variable ITHR, regarding the deployment of HR in the IT area, and $31.4 \%$ of the variance of ITINFR, referring to the deployment of IT resources.

\section{Discussion}

It can be seen that the deployment of IT human resources (ITHR) helps explain the $12.8 \%$ variation in the existence of computer solutions to improve management (ITAPPS) and $12.8 \%$ in the existence of norms and procedures for the use of IT in organizations. However, it only explains $5.8 \%$ of the variation in systems to ensure the functioning of the IT, this last prediction being non-significant. We consider that the first two results are quite logical since an adequate deployment of human resources in the IT area enables the implementation of the automation processes. In other words, to be able to progress in the automation processes, it is not enough to purchase technology, it is also necessary to have the human resources required for the technology to function and be correctly applied. It is also logical that the deployment of human resources also helps and contributes to the development of norms and procedures for the use of IT in organizations, since it is a type of job that is usually associated with the technicians of the area. It is later shown that the existence of norms and procedures improves the users' perception and use of the technologies.

However, it is somewhat surprising that adequate deployment of human resources does not have a positive influence on the guarantee of reliability (i.e., high availability, back-up copies). This may indicate that it is more a question of having sufficient economic resources (and ultimately, technological resources) than anything else. In other words, the non-confirmation of the hypothesis may point to the fact that the need for reliability in the IT area is something already present in organizations and is also a service offered by numerous suppliers.

The basic IT infrastructure (ITINFR) explains $19.0 \%$ of ITAPPS, $20.0 \%$ of ITINFR and $23.2 \%$ of ITRELIAB. Thus, an appropriate level of physical resources in the IT area influences the existence of computer solutions to improve management, the existence of norms and procedures, and the systems to ensure reliable IT functioning. It is interesting to see that all those values are higher than those of the variable ITHR. This means that, although some authors, including Marchand et al. (2000), have indicated that in the implementation of technologies, people must be taken more into consideration than has traditionally been the case, our study indicates that machines and finance are still relevant.

Another interesting result is the extent to which organizations progress in the existence of computer solutions to improve management (ITAPPS); in other words, whether they have applications for the most common tasks, such as publication on the web, workflow management, datawarehouse, single login, etc. We confirm that this variable explains $18.9 \%$ of the technological performance in the organization's activities (ITPERFORG) but is non-significant in the case of technological performance related to users (ITPERFUSER). This indicates that the technological 
output in the organization is explained by the development of automation processes but that, in the case of users, this type of issue is not so important. It should be borne in mind that a good part of the university communities comprises faculty staff and students and that such users do not normally have direct contact with management procedures. Therefore, issues related to the reliable functioning of the technology are more important to them than automation.

With regard to the existence of norms for the use of the technology (ITPROCS), we find that this variable has no significant relationship with performance referring to the technology's contribution to the management of the organization (ITPERFORG). However, it has a significant relationship with, and explains $13.2 \%$ of, the use of the technology by users that are not IT personnel (ITPERFUSER). The non-significance of the first relationship indicates that the use of technology in the organization's management area is not explained by the existence of norms. That finding is logical since the norms for the use of technology are, above all, oriented to the use of technologies on campus, especially by faculty staff (e.g., on the web, and related to respect for intellectual property) and students (e.g., in the use of classrooms, mail and related to respect for intellectual property). Therefore, the significant predictive capability of ITPROCS over ITPERFUSER is logical.

Finally, we analyze the predictive capability of ITRELIAB. We find that it is able to explain $58.4 \%$ of the variance of ITPERFORG but displays no significant relationship with ITPERFUSER. In other words, the implementation of technology in organizations must be accompanied by guarantees that it all functions correctly and that any problems are rapidly resolved. Thus, the continuity of the business is a fundamental issue in the internal use of technology. However, the non-significance of the relationship between ITRELIAB and ITPERFUSER indicates that such reliability is very important and decisive from the management point of view but much less so from the perspective of the use of technology by users.

\section{Conclusions and Implications}

The objective of this study was to expand knowledge of the process of how IT contributes to the performance of higher education institutions. We believe that this work sheds light on the space left by most works between the technological and organizational variables, on the one hand, and organizational performance, on the other. Although our model only goes as far as the phase immediately prior to organizational performance, logic and the opinion of other authors (Sambamurthy and Zmud, 1994; Soh and Markus 1995) suggest that organizational performance is the step that follows technological performance. Thus, we have been able to show a path, based on the results and arguments found in previous literature, of how IT acts to increase technological performance. Moreover, the elements of that value chain are specific links that generate less ambiguity than statements such as a suitable combination of human and technological resources or organizational structures that support the IT tasks. In that respect and except for the work of Bhatt and Grover (2005), the rest of the studies neither generate nor test specific hypotheses regarding the IT-performance process. However, it would be naïve to aim for high specificity about how all the elements of the value chain are managed since that would be too specific to be able to be generalized and applied to different organizations. 
A result of the above is that an overall analysis of the value chain enables university managers to draw many interesting conclusions about how to orient their IT management policies. Thus, this work has shown the importance of planning in the context of technology in higher education. This is the variable that organizes and guides all IT activity and has a direct influence on the two types of resources most studied in the IT-performance literature. Hence, the human resources and the basic IT infrastructure constitute the basis for the development of IT activities. With regard to those activities, our sample contains three that have different effects on technological performance. On the one hand, the existence of computer solutions to improve management, and systems to ensure the reliable functioning of IT (this is determined only by the basic IT resources) that influence the extent to which IT contribute to and support the organization's activities and processes and, on the other, the generation of norms and procedures for the use of technology, which influences the use of technology by non IT-personnel users.

\section{References}

Barclay, D., Higgins, C., Thompson, R.: The partial least squares (PLS) approach to causal modeling: Personal computer adoption and use as an illustration. Technological Studies 2(2), 285-309 (1995)

Barney, J.B.: Firm Resources and Sustained Competitive Advantage. Journal of Management 17(1), 99-120 (1991)

Bharadwaj, A.S.: A resource-based perspective on information technology capability and firm performance: An empirical investigation. MIS Quarterly 24(1), 169-196 (2000)

Bhatt, G.D., Grover, V.: Types of Information Technology Capabilities and Their Role in Competitive Advantage: An Empirical Study. Journal of Management Information Systems 22(2), 253-277 (2005)

Boar, B.: The Art of Strategic Planning for Information Technology. John Wiley \& Sons, Ltd., Nueva York (NY) (2001)

Broadbent, M., Weill, P.: Management by Maxim: How Business and IT Managers can Create IT Infrastructures. Sloan Management Review 38(3), 77-92 (1992)

Broadbent, M., Weill, P., St Clair, D.: The implications of information technology infrastructure for business process redesign. Management Information Systems Quarterly 23, 159-182 (1999)

Brynjolfsson, E.: Beyond the productivity paradox. Communications of the ACM 41(8), 49-55 (1998)

Brynjolfsson, E.: The IT productivity gap. Optimize Magazine 21 (2003)

Chin, W.W.: Issues and opinion on structure equation modeling. MIS Quarterly 22(1), 7-16i (1998)

Cooper, B.L., Watson, H.J., Wixom, B.H., Goodhue, D.L.: Data warehousing supports corporate strategy at first American corporation. MIS Quarterly 24(4), 547-567 (2000)

Francalanci, C., Galal, H.: Information Technology and worker composition: determinants of productivity in the Life Insurance Industry. MIS Quarterly 22(2), 227-241 (1998)

Geisser, S.: A predictive approach to the random effects model. Biometrica 61, 101-107 (1974)

Hitt, L., Brynjolfsson, E.: Productivity, Profit and Consumer Welfare: Three Different Measures of Information Technology Value. MIS Quarterly 20(2), 121-142 (1996) 
Kholi, R., Devaraj, S.: Measuring Information Technology Payoff: A Meta-Analysis of Structural Variables in Firm-Level Empricial Resarch. Information System Research 14(2), 127-145 (2003)

Marchand, D.A., Kettinger, W.J., Rollins, J.D.: Information orientation: people, technology and the bottom line. MIT Sloan Management review 4(41), 69-80 (2000)

Melville, N., Kraemer, K., Gurbaxani, V.: Information technology and organizational performance: An integrative model of IT business value. MIS Quarterly 28(2), 283-322 (2004)

Newbert, S.L.: Empirical research on the resource-based view of the firm: An assessment and suggestions for future research. Strategic Management Journal 28, 121-146 (2007)

Powell, C.T., Dent-Micallef, A.: Information technology as competitive advantage: The role of human, business, and technology resources. Strategic Management Journal 18(5), 375-405 (1997)

Ringle, C., Wende, S., Will, A.: Smart-PLS Version 2.0 M3 (2005), http: / / www.smartpls.de

Ross, J.W., Beath, C.M., Goodhue, D.L.: Develop long-term competitiveness through IT assets. Sloan Management Review 38(1), 31-45 (1996)

Sambamurthy, V., Zmud, R.: IT Management Competency Assessment: A Tool for Creating Business Value through IT. Financial Executives Research Foundation, Morristown (1994)

Schreyer, P.: Information and communication technology and measurement of real output, final demand and productivity. STI Working Paper 1998/2, OCDE (1998)

Soh, C., Markus, M.L.: How IT Creates Business Value: A Process Theory Synthesis. In: ICIS, pp. 29-41 (1995)

Stone, M.: Cross-validatory choice and assessment of statistical predictions. Journal of the Royal Statistical Society 36, 111-147 (1974)

Teo, T.S.H., Ang, J.S.K.: Critical success factors in the alignment of IS plans with business plans. International Journal of Information Management 19, 173-185 (1999)

\section{Appendix I. Constructs and Short Description}

- ITPLAN (Formative construct, 5 indicators). IT planning process.

- ITHR (Reflective, 4). Deployment of HR in the IT area.

- ITINFR (Reflective, 10). Basic IT infrastructure.

- ITAPPS (Reflective, 8). Development of IT applications to automate management.

- ITPROCS (Reflective, 4). Proceduralization of tasks related to norms and procedures.

- ITRELIAB (Reflective, 2). Systems to ensure the IT functioning.

- ITPERFORG (Formative, 6). Performance referring to the contribution of technology to the management of the organization.

- ITPERFUSER (Formative, 6). Performance referring to the use of the technology by non IT-personnel users. 